DOI: $10.20472 / S S .2017 .6 .2 .001$

\title{
A BRIEF ANALYSE ON POST PANOPTIC SURVEILLANCE: DELEUZE\&GUATTARIAN APPROACH
}

\section{EFE BASTURK}

\begin{abstract}
:
The aim of this study is to assemble the post panoptic surveillance techniques with Deleuze\&Guattarian approaches. Although many Deleuzian studies refer to the paradigm of "control society", there is a more important concept in Deleuze philosophy that one could analyze post panoptic surveillance. This concept is "reterritorialization" and Deleuze\&Guattari used this paradigm to explain a rhizomatic power relations occurred in post-capitalist societies. Unlike the limits of the indications belonging control society, reterritorialization may help us to investigate the surveillance on both individualistic and social bases. This article aims to handle the post panoptic surveillance techniques with the concept of reterritorialization which refers to a liquid power passing through the bodies, desires and social at the same time.
\end{abstract}

\section{Keywords:}

Control Society, Reterritorialization, Post Panopticon, Surveillance, Deleuze\&Guattari

JEL Classification: $Y 40, Y 90, Y 50$

\section{Authors:}

EFE BASTURK, Recep Tayyip Erdogan University Faculty of Economic and Administrative Sciences, Turkey, Email: efebasturk83@gmail.com

\section{Citation:}

EFE BASTURK (2017). A BRIEF ANALYSE ON POST PANOPTIC SURVEILLANCE: DELEUZE\&GUATTARIAN APPROACH. International Journal of Social Sciences, Vol. VI(2), pp. 1-17., 10.20472/SS.2017.6.2.001 


\section{Introduction}

The shift from panopticon to post panopticon signifies not only technical developments in surveillance capacities, but also an overflow of surveillance power from panoptic spaces. As Foucault argued, the Panopticon signify a power relation making individual subjects in specific spaces. For example, being a student at school marks a specific power relation watching over the coherence between subject and discursive form. For Foucault, the panoptic power occurred with enclosing the subject in the discursive process in order to make the subject to be a foreseeable individual. This process requires a specific space for power to settle and make itself constant. So, this is the logic of the confinement; power perpetuates itself in confinement by enabling discursive practices surrounding subjects and control the compatibility of the subject with the discursive norms. In panopticon, subjects are not totally governed; rather they are under control by panoptic eye. The logic of the panoptic eye is actually correlate the unrelated elements with each other in order to normalize the power relations. Thus, the aim of the panoptic surveillance is to control this correlation of unrelated elements with each other in certain spaces.

However, in post-panopticon, there is a significant change excluding the necessity of certain spaces. The surveillance in post panopticon does not require a confinement space because it can process without space. That means, surveillance power does no longer need a certain grounding to settle on, rather it can operate like flows. This point is the crucial topic to handle the shift from panopticon to post-panopticon by Deleuze\&Guattarian arguments.

In contemporary surveillance theory, the transformation of panopticon theorized by Foucault to control-society argued by Deleuze, is usually handled by governance techniques. However, the power relations, as Deleuze argued in his postscript, is not an element or structure of governance. Rather it is a flowing of power not confining the subjects from outside but passing through the spaces and subjects. This occurs by terminating the panoptic time-schedule. In panopticon, there is a succession among the spaces; no confinement space processes on subject at the same time, rather they perform one-after-another. In this Foucaultian schedule, there is an external path which the confinement spaces cannot include, so, for Foucault, this path is the possible way to resist to the power relations as it cannot be included. However, as for Deleuze, because the power performs flowing among spaces at the same time, the possibility of externality can no longer be thinkable in control societies.

In this article, my aim is to discuss the post panoptic surveillance with Deleuze\&Guattarian arguments. According to me, discussing post panoptic surveillance with Deleuzian paradigm named control society is not enough to understand surveillance power in late modernity. The argument of control society should be discussed with Guattarian aspect of "reterritorialization" used for understanding capitalistic power. My aim is to connect the argument of reterritorialization with Deleuzian aspect of control society in order to analyze the transformation in surveillance. In the first section, I want to briefly discuss the basic transformations from 
panoptic to post-panoptic surveillance. In the second section, I will offer a Deleuzian perspective on post panoptic surveillance by deepening the argument of control society. In the last section, I will try to associate the post-panoptic surveillance based on Deleuzian paradigm with Guattarian aspect of reterritorialization.

The method I will use in this article is to investigate the differences between panoptic techniques and post panoptic techniques by focusing on Deleuze\&Guattarian approaches. For this reason, the basic method of this study can be considered as 'content analysis'. My purpose is to discuss the conceptual differences between panopticon and post panopticon by focusing the breaks involved into the mentality in surveillance. The differentiation between panoptic context of the surveillance and post panoptic context can be followed in theoretical conceptualizations. For example, in this study panoptic context of the surveillance will be discussed by Foucaultian terms, while the post panoptic surveillance will be discussed by Deleuze\&Guattarian approaches. That's why l'd like to offer a paradigm referring that the differences occurred in surveillance techniques can be realized in specific theoretical conceptualizations.

\section{Theoretical Backgrounds of Post Panoptic Surveillance}

\section{Foucaultian Perspective on Surveillance}

The Foucaultian perspective on surveillance based on Panopticon whose aim is handling the body as a problematical object in a certain space. Panopticon is a process in which body is handled as an examined object and, so, it signals the standardization point. This standardization point marks the proper acts which the individuals should adapt themselves. So, the Panopticon actually means a complex network getting the norm, the discourse, the body and the space been related. Foucault shows us this process by discussing two specific confinement spaces; the prison and the clinic.

In Birth of the Prison (Foucault, 1995), Foucault argued that power in modernity processed by eliminating the "useful" from "wasteful", or more generally, the power based on distinguishing the "normal" and "abnormal". For Foucault, modern power is differed from classical sovereignty. In classical sovereignty, demonstrating the mighty of King was the basic rule; people saw publicly how the King was punishing. The bodies punished and tortured were the spectacle of mighty of the King, therefore the only thing had been expected was to exhibit the limitless power of sovereign. However, this kind of power only based on death; in other words, the sovereign only expected to exhibit his power by issuing sentence of death. So, there was a momentarily asymmetry represented between sovereign and the people in exhibition, and because of this asymmetry based on killing, the sovereign was symbolized as a horrible evil.

On the other hand, with modernity, Foucault sees a critical shifting from sovereignty to power. In sovereignty, the exhibition of mighty on bodies by sentencing them into death is crucial; but power, firstly focuses on keeping bodies alive (Foucault, 2007, p. 155). While sovereignty shows its mighty by torturing or killing the bodies, the power hints its effect by organizing spaces, relations and bodies (Foucault, 1995, p. 82). According to 
Foucault, the core difference is, while the sovereignty targets the living bodies as could be destroyed, the power aims docile bodies which could be controlled. Yet Foucault relates power creating docile bodies with early capitalism needing useful bodies, the main issue how the power exhibits its force not on living bodies but on consciousness depends on a specific technique. This specific technique includes surveillance not only depending on movements of the bodies but calculating the cost of the social itself. In his lecture, Foucault says that although surveillance techniques were once used for singular bodies, then, it started to observe the social itself (Foucault, 2007, p. 29-32).

Although panopticon is a specific technique of surveillance, Foucault analyses panopticon as a broad perspective. For Foucault, panopticon is a governance technique and it depends on controlling the overlap of subject and discourse. Surveillance, then, is the seeking of the standardization point for adapting individual to the subject that power requires. Thus, surveillance can only be practiced in a certain space because of subjectivization requires the observation of the body. When Foucault tells about the clinic, her argues that the clinic should be seen as a space where the bodies are transformed into cognitive objects (Foucault, 2003, p. 8-9). So, Foucault argues that confinement spaces depending on surveillance are the locations of discursive productions of power (Foucault, 2000, p. 350-1). By depending surveillance, power can mark the standardization point and organize the whole social body according to that norm standardized. Discourse, is both basis and production of panoptic surveillance controlling and checking individuals whether they are compatible with the norm standardized or not.

Foucaltian perspective of surveillance could be conceptualized as an adaptive-practices controlling the deviation points in social. Foucault analyzes both clinic and prison in that manner, because these two certain spaces are the locations in which "deviations of the social confined". However, Foucault analyzed surveillance power in a broad way including the daily life. This power is called as panopticism enclosing the social with both deviated and reasonable parts together, but it always reduces one-another. Panopticism is a kind of governance technique depending on a specific surveillance processing with reducing the objects to the norm. That means, panopticism includes both panopticon (surveillance in certain-confinement space) and discursive power (enabling confinement by representing abstract norm) in order to organize the social by adapting alive-independent bodies into docile-subjected bodies.

The clinic and the prison are the leading examples of panopticism, because they signify the surveillance of deviated part of the social (abnormal, prisoner). On the other hand, they control the social indirectly because they are represented as the exclusionary spaces for normal people. Besides, as Foucault argued, the modern daily-routine spaces (school, factory, office, etc.) are designed like panoptic spaces; this is the evidence that modern power controls the normal and routine life like it controls the deviated parts of the social. This is what the panopticism is; normalization of power in daily routines; and surveillance is the basic element of that kind of power. 


\section{Theory-After-Foucault: Post-Panopticon and Surveillance Re-configured}

In the contemporary literature, surveillance has been discussed in two ways: firstly, technical-technological capacity in surveillance has advanced, and secondly, surveillance itself has become a daily routine in the individuals' daily lives. This is called as post panopticon (Boyne, 2000) which signs a shift from panopticon by arguing that surveillance is no longer a power technique, rather it is s "cultural tool" used by individuals. As Mathiesen argued, surveillance does no longer represent a power technique belonging governmental reason, because the fact observing has become an individual-practice in daily life (Mathiesen, 1997). For Mathiesen, today people witness the "continuation of observing" (Mathiesen, 1997, p. 217). That means, surveillance is now also a cultural practice by which individuals set their social relations.

Becoming daily routine of surveillance is also discussed by Bauman. For Bauman, the objects of the surveillance are now the "normal subjects" and mostly their economic activities (Lyon and Bauman, 2012, p. 106). Surveillance is a kind of statistical process of marking the standardization point and Bauman argues that the standardized norm now marks not abnormality but consumption affairs (Lyon and Bauman, 2012, p. 110). Surveillance is mostly used to create data profiles according to what people spend, eat, wear, watch, etc. In panopticon, the aim of power was to immobilize individuals under a normative discourse and get individuals be related with the others under that abstract norm. That means, panopticism transformed individuals to subjects by imposing normative codes which should be represented by individuals. For example, studentship implies a normative code including an acting path which is foreseeable in a certain space. Every individual is located on that discourse and be definable by that process. In other words, studentship means an abstract code including every individual so that immobilize them in a certain space (school) to maintain panoptic power.

Unlike panopticon requiring certain space, post-panopticon does no necessitate confinement spaces. It's because of that in post panopticon the fact space has had a different meaning. The new dimension of panopticon means that surveillance through digital codes or informational process in computer-based technologies (Lyon, 1994, p. 9). In panopticon, surveillance-based technologies were limited, these only focused on controlling the coherence between subject and the norm. However, in post-panopticon, computer-based technologies can observe outside of spaces and any irrelevant facts as well. In other words, through computer-based technologies, surveillance is processed both rapidly and broad aspect; and therefore, surveillance could be everywhere at any time.

Post-panopticon also represents an accumulation of "hyper-information". Because of surveillance depending on computer-based technologies and digital observation process obtains much more information, there is a crucial problem may arise in observation process. The elimination of irrelevant information is the main problem in this context. Because there are lots of information flowing to system at every conduct at any time, and, so, coding could never be ended and confining also can never be defined 
because of limitless information-gathering. So, the main function in surveillance is interpreting the data and, more importantly, collecting them in order to predict the future events. It's one of the crucial differences between panopticon and post panopticon. Because, in panopticon, surveillance depends on information which has already given: for example, when panoptic surveillance targets abnormal, it means that there is an abnormality which has predated to surveillance procedures, so the function of surveillance is just control this deviation which is already defined. However, the postpanoptic surveillance aims to relate the information with the possible events. That means, surveillance becomes a mode of prediction and a specific technique to control the contingency. As a result of that, the power processing in post panopticon radically differs from panoptic power which was limited in certain space.

\section{Deleuze\&Guattarian Paradigm on Post-Panoptic Power and Surveillance}

In this section, I want to discuss how Deleuze\&Guattarian thought would be to understand post-panoptic power in surveillance. As I mentioned above, as post panoptic power is an interpretive involvement on concrete events the power always processes like unpredictable way by surpassing the spaces. The main function of post panoptic surveillance is, then, to correlate the concrete events with interpreting. So, it means that there is an ambivalence in power relations, because the object and target of surveillance are uncertain.

The aim of this section is to investigate how Deleuze\&Guattari's thoughts could be helpful to conceptualize the post panoptic power. Although the Deleuzian aspect of "control society" has recently been used in the surveillance literature, the Guattarian aspects of capitalistic power and theory of reterritorialization would be useful if they were combined with Deleuzian concept of control society. My claim is that Deleuzian concept of control society would be best understood if Guattarian aspects were placed into that power analyses.

\section{Archeology of Capitalistic Power and Reterritorialization}

For Deleuze\&Guattari, capitalistic device is an immanence element of the power itself which processes by capturing the lines of flight (Deleuze and Guattari, 2005, p. 3). Capitalistic power, therefore, should not be reduced into an historical evolution of social. For them, this device works by capturing the desire (potential form of being) and then re-nominate it in another plane. The thought of Deleuze\&Guattari here depends on desire and repression; that's why they reject the idea of an external power. For them, power processes by placing and deriving itself on immanent elements of the body. That means that power does not come from outside, rather it creates itself from the immanent process of the body and conscious as well. Therefore, they handle the desire as the basis of the power; and that power transforms the desire into the new forms. This type of power is nominated as capitalistic which works by shaping the potential creative forces of body to be useful and catchable for power relations. 
Every power type has a distinctive desire regime. This power regime includes both legalized desire codes and repression channels performed on that desire as well. For Deleuze\&Guattari, any social power grounds on repressing the desires (potentiality and contingency), but after then it transforms them into the structured paths. For example, the very sign of the capitalistic power is the Oedipus; through the Oedipal organizer, the desire is firstly forbidden (desire of incest); but after the desire is indicated new paths in which desire to be legalized (Deleuze and Guattari, 2000, p. 92-4). Through the regulator impact of Oedipus, power can reorganize the potentiality as a controllable object. In this context, Deleuze\&Guattari points out how capitalistic power works. By rejecting a desire channel (incest), capitalistic power creates an external and repressive form for the individuals. However, by showing new paths for desire to be evacuated, power becomes an extension belonging to immanence of the body.

This is the reterritorialization as they called. Reterritorialization means that power could maintain its effect by adapting itself to the immanence path of existence. That means, by reterritorialization, power could transform and relate the norms according to bodily impulses. They therefore reject the Foucaultian idea of panopticon handling the power as an external and transcendental to the subject. Rather, they argue that power is not an external to subjects, on the contrary, power is rooted from immanent path. The immanence in Deleuzian philosophy marks a path in which the creative force of the body could derive. However, the very sign of immanence is that it marks a potential existence implying a salvation from any other transcendental path outside of own being. By referring Spinoza, Deleuze uses this conception to warn individuals for a power capturing the immanence belonging them (Deleuze, 1988, p. 28). Capturing, here, means a force oppressing the potential existence of being (potentia) and, then, create the potestas which processes by seizing and confining that potential.

However, instead of processing as an oppressive force, capitalistic power always works to interiorize itself in individualistic forms. As they argue, capitalistic power is not an oppressive power but totally depends on libidinal economy (Holland, 2014, p. 7). That libidinal economy controlling bodies inside basically governs the desire which means the creative force to be outside of the power regime. Historically, the socius gains its meaning by appropriating the naturel forms of things. Primitive socius appropriates the land belonging nature and capitalistic socius appropriates the labour and desire belonging human potential nature (Deleuze and Guattari, 2005, p. 322). That means, with the capitalistic formation of socius, power begins to capture the things from their controllable sides, but not their passive forms. It is the crucial point that the difference between panopticon and post panopticon could be seen by Deleuze\&Guattarian aspects. I want to claim that although surveillance in panopticon depends on monitoring the passive forms of subjects (bodily positioning in panoptic space), the post panopticon aims to monitor the movements or daily practices of subjects and relate these normalized practices with possible facts. That means, while panoptic surveillance monitors subjects in limited purposes and certain spaces, the post panoptic surveillance process in ambiguous way because it nearly targets the whole social practices and relations. So, the surveillance power, which is now able to interiorize the daily routines, 
should be analyzed in a broad perspective. That's why the post panoptic surveillance should be referred with Deleuze\&Guattarian arguments.

\section{Surveillance in Control Society}

In his manuscript, Deleuze deepens the analyze of capitalistic power by relating it with argument of control societies. For Deleuze, the reason why control society differs with panoptic era is that power processes by coding and storing the elements rather it only monitors the objects (Deleuze, 1992, p. 5). The argument of control society marks an intense focusing on monitoring compare to panoptic surveillance, because surveillance techniques and operations have become varied in the control society. The most crucial point what Deleuze argues here is how power operates by surpassing its spatial mechanism. Unlike panopticon, the surveillance in control societies has no spatial power in which individuals are seized to any determined positions. Surveillance in control societies focuses on monitoring movements or acts in flows. Rather panopticon, which operates as a regulator in determined spaces, surveillance power in control society operates as a modulator (Bogard, 1996, p. 21) which works in unlimited gathering processes.

Modulation is a process in which individuals could be coded by a moveable power in their daily routines. This also shows how daily practices of individuals become a problematization of power process because of surveillance processing by modulation focuses on movements which could be reduced into a power relations. In post panopticon the surveillance power has become enlarged because unlike panoptic surveillance, it includes all of the movements in order to code them in an abstract of modulation. Here modulation signifies a crucial point because, by modulation, the surveillance power not only entitles itself only on monitoring the daily lives but also it starts to interpret the activities of individuals whether they are normal or abnormal. So, modulation is a technology which causes the power to intervene the society by coding activities which are handled as "potential risks" by the modulative mentality of power. And, for Deleuze, modulation is the basic element of that kind of power because power could spread itself only by modulation which also enables power to code any contingency in order to embrace the future dynamics (Savat, 2009, p. 51-2). So, this also shows the crucial difference between panoptic surveillance and post panoptic surveillance, because in panopticon the surveillance can only focus on the present time and it can no longer spread itself to any contingency because its scopes and aims are determined in society - such as the guilty, abnormality, etc. are the only topics of that surveillance power. However, in post panopticon, the surveillance is processed on monitoring the contingency in order to manage the future which is unforeseen; and that's why the post panoptic surveillance signifies a power which has an unlimited tendency on capturing and coding the facts into the discursive part of the power.

The reason and basis of a surveillance power to be unlimited tendency on capturing and coding is because of the modulative force of the deterritoralization. As we remember from Deleuze\&Guattari, deterritoralization means a power process which 
intervenes to a fact and break its integrity in itself by coding it in another concept. For instance, as Deleuze\&Guattari called, it's the capitalistic power itself which relates the facts with the process of capitalization. In A Thousand Plateaus, they analyze how that capitalistic power processes by deterritoralization. According to them, power processing by deterritoralization enables to relate itself with the nature of the things; and that's why the capitalistic power neglects the idea in which power is handled as an exterior context to subjects. For Deleuze\&Guattari, by deterritoralization power interiorizes itself to the individuals' objects and tendencies in order to capture the desires which controls the acts of individuals. This is the connection point in which the concept of post panopticon also including the term of control society and deterritoralization figured out by Deleuze\&Guattari joint together. Because, the power deterritoralizating the content from the act and reterritoralizates it in another path which is pre-coded by the power process (Hier, 2003, p. 402). Pre-coding means that power processes not by managing the facts which are external to power forces, rather it operates by modulating the expressions by deterritoralizating them from their contents. As a result of that, power in Deleuze\&Guattarian approach works by deterritoralizating the contents and rather by replacing coded-expressions into that contents (Haggerty and Ericsson, 2000).

The post panoptic way of that kind of modulative and deterritoralizative power is the division of expressions from contents, which means that power processes by modulating the deterritoralized expressions in a path coded by power which refers to reterritorialization itself. In panoptic concept, surveillance operated by power in order to manage the abnormalities in certain spaces (clinics, prisons, etc). These abnormalities are external to power forces and the only aim of power is to manage that abnormalities in order to keep them where they locate. There is no coding here, because the function of coding is relating the facts with contingencies. So, the significant disparity between panopticon and post panopticon could be realized in a way how power handles that external abnormalities and whether it keeps them in differentiated zones or interiorizes them in coded-expressions.

Expressions are the facts deterritorialized by power to exclude it from its content; and this represents the integrity of both content and expression. Integrity, here, refers the externality of the association of expression and content to the modulative power; because this association could not be totally embraced by power relations. So, capitalistic power seeks to capture a gap to deterritorializates the expression from its content in order to locates the expression to the coded relations. For Deleuze\&Guattari, operating of capitalistic power consecutively shows up itself in deterritorializations and reterritorializations. For exemplifying this, they base their argument on Oedipus complexity. For them, capitalistic handling of this complexity is just deterritorializating the desire from its nature [content], and, then, reterritorialization of desire in a social content. This means, capitalistic power firstly alienates the subject to his natural will, then, that power replaces this natural will with a coded-desire. As a result of that, power does not directly forbid the desires of individuals, rather replaces desire [expression] with another content composed by power itself. And, so, this is the modulation and reterritorialization of the expression: not by forbidding the desire, but by opening a new 
path for it, the power captures the desire and distinguishes it from its content. As a result of that, in Oedipal complexity Deleuze\&Guattari see a power relation working by modulating and locating the desire into the coded paths. For them, capitalistic power aims not to limit desires, but reterritorializates the desire to the coded contents filled by capitalistic mechanisms. As Foucault once argued, capitalism seeks productive and docile bodies; however, Deleuze\&Guattari are of the opinion that Foucaultian paradigm is insufficient. This is because of that power does not only aim to produce both docile and productive bodies, but also it seeks to address their desires into the coded paths in order to totally control bodies not in certain spaces, but in flows. This also signifies why Deleuzian argument of control society based on a theory implying that panopticon is already passed over. Because, for Deleuze, the surveillance capacities and power techniques do no longer operates spatially, rather it seeks to enlarge itself to the flows containing daily practices of individuals' which occur beyond spaces. Deleuze adumbrates a new form of capitalistic power which works by focusing on individual tendencies to be modulated and power techniques spreading to the daily routines. This kind of power also shows new form of subjectification processes which connect individual tendencies with modulative mechanisms.

\section{Subjectification in Post Panopticon: Modulation, Reterritorialization and Control}

In contemporary literature, there are some discussions based on new cultural practices of surveillance and its dimensions on daily activities (Mathiesen, 1997; Lyon and Bauman, 2012). In these discussions surveillance is argued as a cultural practice which includes a path of subjectification for individuals to represent and entitle themselves in society. By surveillance practices, individuals manage to integrate themselves into the dominant discursive paths in society; such as images created on media stimulate the desires deterritorialized in order to reterritoralize them in codes. This is the sign of the "viewer society" as Mathiesen called (Mathiesen, 1997, p. 219). Mathiesen argues here, there is a new kind of surveillance occurring in social practices which arises from "above". It's the "sousveillance" which means "surveillance from above. However, Mathiesen adds another concept into that paradigm to resolve the effects of surveillance in social practices. According to him, the age of sousveillance should be named with "synopticon" (Mathiesen, 1997, p. 220) which means a transversal change in surveillance, because, unlike panopticon, the synopticon refers a monitoring of minor groups by majority in society whom represent the images codes which reterritorializate desires. This is what I seek to suggest that Deleuze\&Guattarian concept of reterritoralization here connects with the paradigm of sousveillance and synopticon. Because, synopticon, in which the routine concept of surveillance is reverted, marks a point of subjectification in which individuals are established as subjects by interiorizing the cultural practice of surveillance. Surveillance, here, signs a shift of monitoring from a specific technique (panopticon) and brought to a normalized practice performed by everyone. My aim is to offer a paradigm that this shift could be analyzed with the term 
of reterritorialization, because one could realize why surveillance practices can be related with subjectification process.

\section{Subjectification by and with Reterritorialization}

Since the starting of post modernism, image culture has directed individuals to shape themselves according to the popular images. Especially for Baudrillard, the very factor shaping an managing thoughts and perceptions is the simulacrum, which replaces the image with the truth itself (Baudrillard, 1983). For Baudrillard, subjectivity, society, body and power are configured by semiotics; which is the demonstration of pure visibility. Visibility is the basic element and establisher phenomenon of social relations; so, simulacrum, which is the incentive force of visibility, opens unlimited paths to itself in order to replace truth with semiotics. Semiology, for Baudrillard, is the main principle of reproduction of society, because semiology represents a new truth regime on discourse and subjectification contexts for individuals as well (Baudrillard, 1981, p. 29-63). Every element of visibility is an integral part of semiotics and the sense is established on that process. The meaning of sense does no longer represent a connection between subject and object; rather it is now established by semiotic relationships. Semiology is the replacing of truth, which is intrinsic part of the perception, with the simulacra which does not claim any inherent bond on thought of something. In other words, social relations reduced to semiotics are reproduced only by exchanges of semiotics which represents the sense without any expectation for truth. And it's the reason why our societies have become semiotic-based-society is just because of that the exchange processes are no longer only materialized on commodities, but, rather, the senses are exchanged in this processes. This is what Baudrillard says, "political economy of the sign" which modulates senses to be consumed like commodities.

The political economy of the sign grounds on both exchangeability and reterritorialization of senses belonging to desires. As Baudrillard says in The Consumer Society, the basic dynamic of consumer society is the modulation of individualities like exchangeable things in social relations (Baudrillard, 1998). This is the point of overeconomics, because the whole social relations are reduced into the exchangeable semiotics addressing to desires to be captured and then reterritorialized. In consumer society, relations of production do not include only commodities and labor forces under the determination of capital; but they also include desires, tendencies, expectancies, etc. to give a meaning to commodity itself. The commodities are no longer just "things", but they also have a meaningful content which connects the individuals' desires with the concrete materiality of the commodity (Baudrillard, 1998, p. 53). By transformation of "thing" to the "meaning", subjectification has a new context, especially on transverse the exchanges of commodities to the exchanges of semiotics. In panoptic age the subjectification was basically connected to relations of production. And the relations of production including subjectification processes were designed by disciplinary structures whom functions were to locate labor forces where they had to be, to multiply bodily forces and to secure the social by confining the risky people into the certain spaces. 
However, in post panoptic age, the subjectification has located on a ground in which bodies are not standardized (make them docile or productive), but they are made themselves to demonstrate as a semiotic element to be consumed in exchange of sign systems.

The political economy of the sign works by demonstrating the body and subjectification, especially it enforces the subjectification to be unique and irreducible. Unlike panoptic surveillance, in which bodies were planned to be standardized by power, post panoptic surveillance refers cultural practices in which individuals are getting to be subjects by monitoring other people in order to make their beings meaningful. The semiology of the political economy of the sign works by deterritorialization of the meanings in order to be reduced into the gaze which constantly and flowingly occurs. The difference between surveillance and gaze should be realized here, because gaze refers a practice by which desires deterritorialized could be located into the coded identities capturing these desires and denominate them. This is the reterritorialization, which firstly separates desires from being and then locate them in another context. My claim is to offer that the reterritorialization should be understood as a function to be exercised by the modulative forces of the society; and these forces also set up a subjectification process in which individuals make them subjects by functioning the gaze. The gaze, here marks a process which correlates the desires and codes; and post panoptic power works by creating and demonstrating these codes to people in order to modulate them with these codes. Therefore, the subjectification in post panopticon surpasses the panoptic subjectification, because while post panopticon could encompass the daily routines and normalized practices of individuals, panopticon could only focus on abnormalities in order to functioning the subjectification processes.

\section{Control}

Today the culture of surveillance is not formed of a surveillance power making bodies to be monitored and visible, rather it works a daily routine and includes the people's activities. In other words, the new context of subjectification processes is not produced by power relations confining and limiting bodies in certain spaces or determined and behavioral codes, rather it is formed by the people who are getting to be the active agents of surveillance practices. So, in post panoptic era, the visibility is no longer a "trap", but a desire for subjects in order to designate themselves to the popular iconographic representatives which are monitored by majority in public sharing areas (social media, TV shows, advertisements, etc.). So, visibility is now the process of an individual to getting himself be iconized and to be monitored by other people. Visibility is somehow a kind of proof of the being, because without visibility or any other demonstrating the bodily existence, the being is getting to be senseless. It's the fact what Baudrillard wishes to argue on the political economy of the sign is that the visibility is now a meta-semiotics in which individuality is established to be consumed, and, on the other hand, visibility is a power process by which the expressions of individualities are constantly corresponded to the codes. So, individuals and their acts are not 
monitored, but their tendencies are followed and the power seeks to capture, and then, locate the desires into the foreseeable codes determined by the reterritorialization processes. It's the main disparity how surveillance power works in post panopticon versus the power in panopticon which only focused on managing bodies in order to make them docile in certain and confined spaces.

In post panopticon, the surveillance power surpasses the spatial confinement; rather, it frees the bodies and more importantly it stimulates individuals to express their desires in order to captures and relates the desires with determined codes. As Jameson said, it's the "condensation of semiotics" (Jameson, 1984, p. 112); because everything is getting to be cultural in late capitalism (Jameson, 1991, p. 46). Jameson wants to claim that the communication between unique and irreducible individuals are lost, because the cultural and political economy of semiotics encompasses every point of the social and make the society to be "imaged-society".

The imaged-society differs from the production-centralized society by organizing not production elements - such as time, labor force, spatial arrangements, disciplinary forms, etc. - but the consumption factors - for instance forms of subjectification which are brought to be consumed and to be the issue of exchange of identities. The main result of this differentiation can be seen on some parts: for instance, the spaces are not configured in order to function the disciplinary power over bodies, but the spatial arrangements are now structured as a "perfect and limitless world" in which desires and tendencies are addressed by socially codes. In iconographical society, people seek to capture images which are the sign of their deterritorialised desires; so, the spatial arrangements address these relationships by including demonstrable icons and images by which tendencies can be reterritorialized.

On the other hand, mentioning of consumption or culture of gaze necessitates the keeping flexibility on mind rather than disciplinary elements of panoptic society. While the production-centralized society is the sum of the processes subjecting bodies within capitalized forms, the consumer society seeks to diverse people in order to individualize for them to express their uniqueness. In consumer society, the images are shown as the identification points in which individuals make their uniqueness real by modulating themselves in these codes in order to be the very focus of the gaze. Because of everything is reduced to semiology, the gaze itself has a specific and unique character in consumer society paradigm. As Ewen argues (Ewen, 1988), the semiotics of desires are starting to be the represents of the simulacra, rather than truth, or the possibility at best. New culture of gaze is functioned by people who naturally seek to surpass their realities by simulacra presented them to reterritorialize their desires in a new form of space. This new space is called as "virtual" which means a spatial arrangement surpassing the truth and replacing it with simulacrum or fantasies imagined by individuals. In virtual spaces, individuals could address their phantasms with codes, and, so, their phantasms are getting to be reterritorialized. The reality of relationship inter-bodies is invalid in virtual spaces, because these spaces include new form of social relationships which are designed according to the culture of simulacra. In these spaces, people can exteriorize what they don't see; so, the world is presented as a perfect and 
utopic thing in these spaces because it is full of with the phantasms or desires belonging individuals who seek to exclude reality from their real lives. This techno-universe socializes the individuality in virtual spaces and personal identities are publicized by virtual relationships. The communication on virtual space comforts people because there is no physical contact with the "other" in there; so, people start to seek to have more secure and comfortable spaces in which they contact with environment without any fear or anxious.

The culture of gaze in virtual spaces does also refer a specific power technique which focuses on bodies from apart and monitor the acts of bodies by technologized control devices (Norris, McCahill and Wood, 2004, p. 118). Surveillance technologies moved into electronical platforms start to code information which is gathered from different places. The specific working of this new technology includes an advanced program which relates different types of data with each other and create a profile based on these data sets. This is one of the disparities between panoptic surveillance and post panopticon, because although subjectification in panopticon referred a power processing in determined aims and scopes, post panopticon refers a contingent creation of profiles gathered from elsewhere. In other words, while panopticon focused on certain type of data, post panopticon tends to duplicate data sets in order to create a profile which also embraces future being of the individual. And it's so important that because this kind of surveillance technology does inevitably obscure the line with normalabnormal, innocent-guilty, etc. by relating data sets with each other which are gathered from any act of individuals'. So, scopes of power and criterions of normality [and abnormality] are both obscured by this kind of surveillance; because post panoptic technologized surveillance works not by monitoring the selected individuals, but by relating and coding activities of any individuals being both normal and abnormal.

There is another problem occurs in post panopticon which marks a fact that surveillance is no longer processed by managerial staff, but is exercised by machines or electronic devices. According to G. T. Marx (Marx, 1988), surveillance is now processed by machines whom are authorized on gathering, coding and interpreting (Marx, 1988, p. 218). The very mission of the machines is not only the gathering of information, but interpreting and coding them. This refers a critical threshold in which people would envision like machines and they would start to perceive the world from the machinic eyes in a short while.

As Zuboff argued (Zuboff, 1988), there is another theme in surveillance called as "interface" which refers a profile created by the machinic process of gathering-coding. Today, as we can see, digital spaces are not the only platforms in which records belonging to people are hided, but also these spaces include our digital-profiles like our secondary identities. This kind of identity is totally virtual and it is freed from the real lives of people. According to Zuboff, as the companies starts to record the worker's performances or activities in machinic process, the companies do have a chance to create profiles of workers which include foreseeable data for the company in order to manage the future contingencies (Zuboff, 1988, p. 323). The most important thing is that machinic process does not only work in work-time schedule, but also it encompasses the free times of 
workers; for example, the machine records whether any worker could provide feedback quickly or they could be suitable for making them to work whether they are out of work. Especially communicate with e-mails or cell phones provide companies to enlarge the working time of workers. This machinic networks of surveillance can relate within different areas of acts and that's why gathering gains more important role in that kind of monitoring processes. The disciplinary relations inside the work-space has gradually overflowed to outside and starts to incorporate the free times into the work-times. The reason why the inside and outside of work areas are become obscured is because of surveillance-on-bodies becomes dataveillance (Clarke, 1988, p. 499). Dataveillance is a process in which bodies are coded as numbers or signs which are totally digital in virtual spaces. Dataveillance does not need moveable bodies; as it works with codes, it constantly manages to create profiles in and by virtual processes. The body is perceived as a code which can be transferred once to virtual context, then it's easy to interpret and subject that code into the profiles created. The creating and documenting profiles has no end; because it is always modulated with any act.

\section{Conclusion}

As stated in the introduction, the main purpose of this study is to suggest that the differences in the surveillance can be understood through a specific content analysis. Unlike to other methods, content analysis is intended to examine conceptual transformation not only in abstract context but also in facts. For this reason, the method used in this study should not be considered only as an abstraction attempt. Rather, this study attempts to examine the differences in surveillance by relating conceptualize with the facts.

An example of the discussion of the relationship between concept and phenomenon can be followed in overlapping points between subjectification and control regimes in postmodern age. My main claim is that present power techniques based on surveillance do modulate themselves into the individual tendencies by normalizing the control mechanisms. This signs the differentiation of post panopticon from panopticon because unlike panopticon, post panopticon does not configure an asymmetrical position between subjects and power; rather it seeks to process in subjectification stages.

Surveillance gains a very strategical position in the age of post panopticon, because the fact monitoring itself has become a daily practice. Monitoring in panopticon processed by a surveillance power modulating bodies which were handled as abnormality; so, the aim of the panoptic surveillance was totally determined which focused on rehabilitating the abnormalities in social body. However, in post panoptic age the aim of surveillance has been radically different, because surveillance itself has become a cultural context which is practiced by people normalizing control techniques. Here, the problematization arises that how one could analyze the differentiation between panopticon, in which surveillance belonging power mechanisms, and post panopticon, which provides people can participate in. 
According to me, post panoptic surveillance which is handled as a cultural exercise should not be considered with Foucaltian arguments; so, I claim that Deleuze\&Guattarian aspect on capitalistic power is more useful to understand how power and control techniques are joint with subjectification or individual tendencies. The Deleuze\&Guattarian concept of deterritorialization/reterritorialization should be invoked here to analyze how these two processes can be nested within each other. As aforementioned above, they handle reterritorialization by referring a relation connecting desire with power processes. Unlike panoptic regime, in which individuals are produced as docile subjects, post panoptic regime tries to free the individuals to express their desires. By getting people to express their desires [pure individuality], power could overlap the content belonging to itself with individualities. For Deleuze, any power structure brings an emotional model to the souls and reproduce itself from there (Hume). In other words, the Deleuzian aspect on power relations remind us any power relation must capture an impulsion inside of individuals by which power could address their desires, tendencies and motivations with its elements. That means power could process only by modulating itself to individual impulsions and demonstrating these motivations in itself. Since the post panoptic surveillance techniques have increased and have diversified, analyzes on power must include the joint momentums of individuality and control techniques and must try to figure out how they have been able to attached each other. Here is what Deleuze\&Guattarian aspects on power analyses can help us to try to understand and criticize the situation.

\section{References}

BAUDRILLARD, J. (1981). For A Critique of the Political Economy of the Sign, tr. Charles Levin, New York: Telos Press

BAUDRILLARD, J. (1983). Simulations, tr. P. Foss, P. Patton and P. Beitchman, New York: Semiotext(e)

BAUDRILLARD, J. (1998). The Consumer Society: Myths and Structures, London: Sage

BAUMAN, Z. and LYON, D. (2013). Liquid Surveillance A Conversation, Cambridge: Polity Press

BOYNE, R. (2000). "Post-Panopticism", Economy and Society, 29(2), pp: 285-307. https://doi.org/10.1080/030851400360505

CLARKE, R. (1988). "Information Technology and Dataveillance", Communications of the ACM, 31(5), pp: 498-512. https://doi.org/10.1145/42411.42413

DELEUZE, G. (1988). Spinoza: Practical Philosophy, tr. R. Hurley, San Francisco: City Light Books

DELEUZE, G. (1992). Postscript on the Societies of Control, October, Vol. 59, pp. 3-7

DELEUZE, G. and GUATTARI, F. (2000). Anti-Oedipus Capitalism and Schizophrenia, tr. R. Hurley, M. Seem and H. R. Lane, Minneapolis: University of Minnesota Press

DELEUZE, G. and GUATTARI, F. (2005). A Thousand Plateaus, Capitalism and Schizophrenia, tr. B. Massumi, London: University of Minnesota Press

EWEN, S. (1988). All Consuming Images, New York: Basic Books

FOUCAULT, M. (1995). Discipline and Punish Birth of the Prison, tr. A. Sheridan, New York: Vintage Books 
FOUCAULT, M. (2003). The Birth of the Clinic an Archeology of Medical Perception, tr. A. M. Sheridan, New York: Routledge

HAGGERTY, K. D., ERICSON, R. V. (2000). "The Surveillant Assemblage”, British Journal of Sociology, 51(4), pp: 605-22. https://doi.org/10.1080/00071310020015280

HIER, S. P. (2003). "Probing the Surveillant Assemblage: on the Dialectics of Surveillance Practices as Processes of Social Control”, Surveillance \& Society, vol. 1 (3), pp: 399-411

HOLLAND, E. W. (2001). Deleuze and Guattari's Anti-Oedipus Introduction To Schizoanalyses, New York: Routledge

JAMESON, F. (1984). "Postmodernism and the Consumer Society", H. Foster (ed), in Postmodern Culture, London: Pluto Press

JAMESON, F. (1991). Postmodernism, Or the Cultural Logic of Late Capitalism, Durham: Duke University Press

LYON, D. (1994). The Electronic Eye The Rise of Surveillance Society, Minneapolis: University of Minnesota Press

MATHIESEN, T. (1997). "The Viewer Society: Michel Foucault's 'Panopticon' Revisited", Theoretical Criminology, 1(2), pp: 215-234. https://doi.org/10.1177/1362480697001002003

NORRIS, C. MCCAHILL, M. WOOD, D. (2004). "Editorial. The Growth of CCTV: a global perspective on the international diffusion of video surveillance in publicly accessible space", Surveillance \& Society, 2(2/3), pp. 110-135

SAVAT, D. (2009). "Deleuze's Objectile: From Discipline to Modulation", Mark Poster and David Savat (ed), in Deleuze and New Technology, Edinburgh: Edinburgh University Press, pp: 45-63

ZUBOFF, S. (1988). In the Age of the Smart Machine, New York: Basic Books 